\title{
HIV/AIDS em Tempos de Retrocesso: Possibilidades de Atuação na Educação Básica
}

\author{
VIH / SIDA en Tempos de Retrocesso: Posibilidades de Atuação na \\ Educação Básica
}

\author{
HIV / AIDS in Times of Withdrawal: Possibilities of Performance in Basic \\ Education
}

\author{
Peterson Fernando Kepps da Silva ${ }^{1}$ \\ Lavínia Schwantes ${ }^{2}$
}

\begin{abstract}
Resumo
No Brasil, o número de casos de HIV de 2007 a 2018 registrados foram de quase 250 mil, sendo a região sudeste e sul, respectivamente, as mais acometidas. Já o número de jovens que contraem a doença vem aumentando no país, o que nos faz pensar na escola como uma ferramenta potente de discussão sobre o tema. Diante disso, desenvolvemos atividades com duas turmas de oitavos anos do Ensino Fundamental do município de Pelotas RS e visamos apresentar neste trabalho metodologias de ensino endereçadas para Educação Básica que possam contribuir com a ampliação de conhecimentos e informações de jovens estudantes sobre HIV/AIDS. Para tanto, estabelecemos parceria com uma Unidade Básica de Saúde por meio do Programa Saúde na Escola. A parceria contribuiu para que tivéssemos atividades mais aproximadas do contexto da escola. Consideramos os resultados das atividades satisfatórios, tendo em vista a participação e interação dos estudantes diante das discussões e trabalhos propostos.
\end{abstract}

Palavras-Chave: HIV/AIDS; ensino de ciências; educação básica; PSE; metodologias de ensino.

\section{Resumen}

En Brasil, el número de casos de VIH reportados entre 2007 y 2018 fue de casi 250 mil, siendo el sudeste y el sur, respectivamente, los más afectados. El número de jóvenes que contraen la enfermedad ya está aumentando en el país, lo que nos hace pensar en la escuela como una herramienta poderosa para la discusión sobre el tema. En vista de esto, desarrollamos actividades con dos clases de octavo grado de la escuela primaria en la ciudad de Pelotas - RS y pretendemos presentar en este trabajo metodologías de enseñanza dirigidas a la educación básica que puedan contribuir a la expansión del conocimiento y la información de los jóvenes estudiantes sobre el VIH / SIDA. Con este fin, nos asociamos con una Unidad Básica de Salud a través del Programa Salud en la Escuela. La asociación nos ayudó a tener actividades más cercanas al contexto escolar. Consideramos que los resultados de las actividades son satisfactorios, dada la participación e interacción de los estudiantes en las discusiones y el trabajo propuesto.

Palabras-clave: VIH / SIDA; enseñanza de ciencias; educación básica; PSE; metodologías de enseñanza.

\begin{abstract}
In Brazil, the number of HIV cases reported from 2007 to 2018 was almost 250 thousand, with the Southeast and South, respectively, being the most affected. Already the number of young people who contract the disease is increasing in the country, which makes us think of school as a powerful tool for discussion on the topic. In view

\footnotetext{
${ }^{1}$ Mestre em Educação em Ciências; Programa de Pós-graduação em Educação em Ciências (PPGEC-FURG); Rio Grande, Rio Grande do Sul, Brasil; keppspeterson@ gmail.com

${ }^{2}$ Doutora em Educação em Ciências; Programa de Pós-graduação em Educação em Ciências (PPGEC-FURG);

Rio Grande, Rio Grande do Sul, Brasil; laviniasch@gmail.com
} 
of this, we developed activities with two eighth-grade classes of Elementary School in the city of Pelotas - RS and aim to present in this work teaching methodologies addressed to Basic Education that can contribute to the expansion of knowledge and information of young students about HIV / AIDS. To this end, we partnered with a Basic Health Unit through the Health at School Program. The partnership helped us to have activities closer to the school context. We consider the results of the activities satisfactory, given the participation and interaction of students in the discussions and proposed work.

Keywords: HIV / AIDS; science teaching; basic education; PSE; teaching methodologies.

\section{Introdução}

O início da década de 1980 é marcado pelo "aparecimento" de uma "doença nova", um "germe" que a própria ciência desconhecia a sua origem e formas de transmissão. $\mathrm{O}$ HIV/AIDS (vírus da imunodeficiência humana / Síndrome da Imunodeficiência Adquirida tradução em português) emergia e instaurava no mundo um clima de incertezas, dúvidas e segregação de grupos. As confirmações de cada vez mais casos em homossexuais masculinos adensaram a marginalização desta parte da população. A título de exemplo, o termo "peste/câncer gay", relegou aos homossexuais e transexuais o fator principal de multiplicação da doença. E mulheres heterossexuais ainda não eram tidas como "grupo" a ser atingido pelo vírus. Em meio a um cenário caótico, o HIV/AIDS assumia o status de pandemia, soterrava a revolução sexual conquistada nos anos de 1970 e ditava outras formas de relações e contato afetivo-sexual.

A história do HIV/AIDS, até chegar a um momento de maiores entendimentos e "controle", perpassou por caminhos tortuosos como a testagem de diferentes retrovirais/coquetéis - uma espécie de combinação de medicamentos destinados a conter a multiplicação do "vírus mutante", com altos efeitos colaterais; a revelação de figuras públicas como portadoras da doença; falta de informações sobre a transmissão; a surpresa de que mulheres, via sexo vaginal, também poderiam ser infectadas; e a morte de milhares de indivíduos que entrassem em contato com o vírus.

Um ponto a ser considerado é que o vírus já circulava, a despeito de qualquer teoria de origem, nos países africanos ${ }^{3}$. Entretanto, só passou a ser objeto de estudo e análise quando acometeu países desenvolvidos economicamente, especificamente os Estados Unidos da América, onde foi registrado o "primeiro diagnóstico". Ou seja, entendemos que o HIV/AIDS só passou a ser considerado um problema mundial, se tornou matéria frequente de notícias, foi categorizado efetivamente como epidemia e pandemia e recebeu investimentos de órgãos

\footnotetext{
${ }^{3}$ Disponível em: http://g1.globo.com/ciencia-e-saude/noticia/2014/10/aids-surgiu-no-congo-nos-anos-20concluem-investigadores.html. Acesso em: 03 dez. 2019.
} 
governamentais e não governamentais para a pesquisa e a atenção da ciência quando atingiu um determinado "tipo" de população e sujeitos.

No Brasil, o início da década de 1980 caminhava para o fim do regime ditatorial uma fase considerada e vivenciada de maneira mais festiva, de risos, alegria, de liberdade sexual. Relatos do período expõem que no imaginário de muitos a AIDS era mais uma invenção (uma espécie de boato) de ditadores para combater todo o avanço libertário que acenava. Mas as semanas foram passando e os números de casos entravam em ascensão, assim como o índice de mortalidade era extremamente alto. A "invenção" se tornava realidade e o contágio uma sentença de estigma e morte.

O HIV/AIDS "tinha cara”, a aparência extremamente magra e o aspecto debilitado manifestado pelos portadores se tornavam evidente logo após o contágio; porém, foi a partir dos anos de 1990 que o cenário passou a se alterar, com grandes investimentos em pesquisas científicas e avanços na medicação e com maiores conhecimentos passamos, enquanto sociedade, a compreender o funcionamento do vírus no sistema imunológico (de defesa) dos seres humanos. Para se ter ideia, as notificações da doença se iniciaram por volta de 1981 e entre 1983/1984 foi divulgada a descoberta do vírus pela ciência. Houve uma fase dominada pelo desconhecimento não só da população em geral (aqui cabe lembrar também o papel discriminatório adotado pela igreja católica) que propagava informações equivocadas e alicerçadas em preconceitos e segregação (ALMEIDA e LABRONICI, 2006).

Em contrapartida, no Brasil, organizações começaram a surgir. Neste momento, cabe sublinhar o Grupo de Apoio a Prevenção à AIDS (Gapa $\left.{ }^{4}\right)$. Um grupo que se originou em São Paulo, a partir da união entre uma parcela da população (principalmente homossexuais acometidos pela doença, amigos desses e familiares) e médicos interessados em compartilhar informações e esclarecer, na medida em que os conhecimentos da época permitiam, dúvidas sobre a AIDS. De maneira muito sintética, o GAPA, de forma forte e organizada, buscou combater preconceitos, propagar informação e conhecimento, assim como se envolveu juridicamente em inúmeros casos que envolviam desde treinamento de advogados até distribuição do coquetel e reintegração ao trabalho por portador de HIV/AIDS.

Figuras públicas também tiveram papel importante no combate à desinformação e ao estigma e discriminação relacionadas ao HIV. O sociólogo Herbert José de Sousa, popularmente conhecido como Betinho, em entrevistas, dizia que as pessoas tinham medo da

\footnotetext{
${ }^{4}$ Disponível em: http://agenciaaids.com.br/artigo/por-que-o-grupo-de-apoio-a-prevencao-a-aids-gapa-subsisteha-30-anos/. Acesso em: 03 dez. 2019.
} 
AIDS tanto pela morte quanto pelo estigma. Já o cantor, compositor e poeta Cazuza (Agenor de Miranda Araújo Neto) teve a sua "cara" exposta em revista e lutou febrilmente contra o vírus. Cazuza admitiu a AIDS na vida e na música, nas falas contundentes em entrevistas criticava a "caretice" da direita e da igreja e o desserviço prestado por elas. Na arte, mesmo em meio ao tratamento da doença e com aparência debilitada, surgiam músicas e disco que escancaravam sua condição e força contra a doença.

Após quase 40 anos do dito "início" da epidemia, tem-se notícias ${ }^{5}$ divulgando a cura de pacientes com HIV - o que evidentemente não pode ser extrapolado para todos os indivíduos ou ser traduzido como a "cura da AIDS". Por outro lado, no Brasil, o número de casos da doença de 2007 a 2018 registrados foram de quase 250 mil, sendo a região sudeste e sul, respectivamente, as mais acometidas. Já os casos de AIDS, isto é, a manifestação das doenças oportunistas devido à ineficiência das células que defendem o corpo, de 1980 até 2017, também possui a região sudeste e sul com maior número de óbitos notificados, em torno de 325 mil (BRASIL, 2019). Estes dados ainda nos revelam que o número de jovens que contraem a doença vem aumentando, o que nos faz pensar na escola como uma ferramenta potente de discussão sobre o tema.

Tendo em vista o contexto do país, cabe lembrar que atualmente foi extinto o departamento de HIV/AIDS do ministério da saúde ${ }^{6}$. Entendemos, com isso, que trazer para a arena da discussão HIV/AIDS no espaço escolar se faz necessário. Aproveitar disciplinas como a de Ciências, que já possui na grade curricular assuntos como: sistemas do corpo humano, vírus e célula, pode facilitar esta inserção e possibilitar aos estudantes maiores informações e ampliação de conhecimentos. Além disso, programas como PSE (Programa Saúde na Escola) pode corroborar para a construção de um olhar mais atento e crítico no que tange à saúde e o cuidado de si.

O PSE objetiva interseccionar a escola com uma unidade básica de saúde (ou outras entidades públicas), nas quais trabalham de forma integrada, por meio de diferentes ações e projetos, para a prevenção de doenças, cuidado com a saúde e o enfrentamento de vulnerabilidades que possam comprometer o desenvolvimento tanto de crianças quanto adolescentes da rede pública de ensino (PSE, 2019). Como pode ser constatado, o PSE tem a

\footnotetext{
${ }^{5}$ Disponível em: https://g1.globo.com/ciencia-e-saude/noticia/2019/03/04/cientistas-relatam-segundo-caso-decura-do-hiv-apos-transplante.ghtml . Acesso em: 03 dez. 2019.

${ }^{6}$ Disponível em: https://noticias.uol.com.br/saude/ultimas-noticias/deutschewelle/2019/04/29/governobolsonaro-preocupa-entidades-de-combate-a-aids.htm. Acesso em: 03 dez. 2019.
} 
atuação de professores, gestores e profissionais da saúde, que desenvolvem em parceria atividades para alcançarem tais objetivos. Ademais, leva-se em consideração o contexto no qual a escola está inserida, suas principais necessidades, bem como seu Projeto Político Pedagógico - documento que exprime a proposta pedagógica da escola.

Diante disso, visamos neste artigo apresentar metodologias de ensino endereçadas para Educação Básica que possam contribuir com a ampliação de conhecimentos e informações de jovens estudantes sobre HIV/AIDS.

\section{Detalhamento das atividades e discussões}

Ao longo de 2019, foram desenvolvidas diferentes atividades nas aulas da disciplina de Ciências com o objetivo de apresentar o que é o HIV/AIDS e formas de contágio; traçar um breve histórico da doença; bem como discutir sobre carga viral indetectável, testagem, tratamento e, também, questões sociais da atualidade, como o alto índice de jovens que estão contraindo o vírus. Escolhemos estes pontos a serem desenvolvidos com os alunos a fim de esboçar um panorama da doença no país, suas implicações biológicas (os afeitos no corpo humano), sociais e políticas. Diante de tudo isso, visamos ainda, não construir uma ideia de "terror ou pânico", com frases de efeito como "AIDS mata" ou "Não tem cura". Nossa ideia foi promover momentos de reflexões sobre a doença a partir de diálogos não extremistas ou sensacionalistas.

Um dos autores deste trabalho, professor titular da disciplina de Ciências na rede básica de ensino do município de Pelotas - RS, no ano de 2019, desenvolveu as atividades mencionadas em duas turmas de oitavos anos do Ensino Fundamental. O ano/série foi escolhido pela facilidade de intersecção com os outros conteúdos programados para os trimestres. Os assuntos envolvem corpo humano, especificamente os sistemas, nos quais podem ser entendidos como um conjunto de órgãos e estruturas que atuam de forma integrada para realização das funções do corpo humano. Além disso, a idade dos alunos está entre 13 e 15 anos, período de pré-adolescência, ou seja, de mudanças intensas tanto biológicas quanto sociais.

Cabe destacar que as ações foram planejadas em parceria com a UBS (Unidade Básica de Saúde) a partir do PSE. O que significa dizer que discutimos com profissionais da saúde os mecanismos de trabalho bem como recebemos materiais, como folder informativo sobre HIV/AIDS a ser disponibilizado para os alunos, e nos interemos de dados como o alto número de jovens e idosos com HIV registrados no município de Pelotas - RS. 
Sabendo disso, podemos, então, traçar de forma mais detalhada as propostas pedagógicas desenvolvidas. No início do ano letivo de 2019, desenvolvemos uma aula teórica expositiva (duas aulas seguidas de 45 minutos cada) para apresentar o que é HIV/AIDS, a diferença entre as siglas, e o que isso representa para o corpo humano. Em seguida, ainda de forma teórica e dialógica, discutimos as formas de contágio. Os alunos interagiram muito, questionaram sobre alguns mecanismos de contágio, como beijo em pessoas que usam aparelho ortodôntico e relataram casos de familiares, amigos ou vizinhos com a doença. De modo a darmos continuidade neste assunto e mobilizar a interação entre os saberes dos estudantes, propomos o jogo, inspirados no livro de RIBEIRO et al. (2008), “'Fala sério' ou 'Com certeza' sobre HIV/AIDS”. Para isso, dividimos a turma em dois grandes grupos para responderem as afirmativas postas no quadro abaixo:

Quadro 1 - afirmativas utilizadas no jogo "fala sério" ou "com certeza" sobre HIV/AIDS.

\begin{tabular}{|l|}
\hline 1) Compartilhar seringas é uma das maiores causas de contaminação do HIV entre usuários de drogas. \\
\hline 2) Sexo anal é uma das formas de contaminação pelo HIV. \\
\hline 3) Beijo na boca não é uma das formas de contaminação pelo HIV. \\
\hline 4) Usar um mesmo talher de um portador de HIV não causa risco de contaminação. \\
\hline 5) Cuidado no ônibus! Não sente e nem toque em nada, você pode ser infectado pelo HIV. \\
\hline $\begin{array}{l}\text { 7) Usar a mesma toalha para secar o rosto provoca a contaminação pelo HIV. } \\
\text { frequentadores da academia através dos aparelhos de ginástica. }\end{array}$ \\
\hline 8) Sexo sem preservação não apresenta risco de contaminação de DST/AIDS. \\
\hline 9) Sentar no sanitário pode ser um meio de transmissão do vírus HIV. \\
\hline 10) Uma pessoa com aparência saudável é uma pessoa sem HIV. \\
\hline 11) A transfusão de sangue é uma forma de transmissão do vírus da AIDS. \\
12) Fazer uma tatuagem ou colocar um piercing com material não esterilizado não representa nenhum risco de \\
contaminaço à pessoa.
\end{tabular}

13) Na hora do parto normal pode ocorrer a infecção do vírus HIV da mãe para o filho, caso ela seja portadora.

14) Uma mãe portadora do HIV ao amamentar seu filho pode infectá-lo com o vírus.

15) Manter relações sexuais sem camisinha não tem nenhum problema.

16) Sexo oral é uma forma de transmissão do HIV.

17) A primeira vez não pega HIV.

Fonte: RIBEIRO et al. (2008)

De forma geral, os alunos tiveram facilidade em responder as perguntas que tratam da transmissão do HIV por via sexual ou do compartilhamento de artefatos cortantes. Entretanto, 
as perguntas que envolvem beijo, aperto de mão, sentar no mesmo lugar ou então de acesso a instrumentos/materiais não cortantes pelos portadores de HIV, geraram discussões e discordâncias nos grupos. A título de exemplificação, grande parte de um grupo acreditou que “com certeza" o assento de ônibus, quando ainda está aquecido pelo calor do corpo, pode transmitir o vírus. Também afirmaram que a transmissão do HIV na primeira relação sexual não seria possível. O que nos indica o quanto o desconhecimento é alto e que informações equivocadas sobre o vírus se propagam no meio social e assumem caráter de verdade.

Buscamos ao longo da resposta de cada grupo pontuar onde estava o erro, o porquê de estar equivocada a resposta, assim como atentar para a segregação que informações como as mencionadas no parágrafo anterior podem causar. De modo geral, a vivência da soropositividade é percebida de forma negativa e excludente pela sociedade, na qual culpabiliza os infectados e reconhece grupos como "homossexuais", "prostitutas" e "dependentes de alguma droga" como vetores, isto é, indivíduos transmissores da doença (GUIMARÃES e FERRAZ, 2002). E, desse modo, a ideia de grupo de risco ganha relevo, esquecendo-se que são comportamentos e atitudes que podem nos colocar em contato, ou não, com o vírus - não grupos considerados "desviantes", que fogem do padrão afetivo-social estabelecido e, assim, acabam por ser estigmatizados.

Com o intuito de melhor ilustrar as discussões já promovidas, apresentamos, no mês de março e no período de duas aulas, o documentário "35/20: Do pânico à esperança", produzido pelo canal fechado de televisão GloboNews e disponível na íntegra gratuitamente pelo site ${ }^{7}$. Por meio de relatos de jornalistas, médicos, especialistas que lidam com a epidemia no Brasil desde o início, e pessoas com status sorológico positivo para o HIV, o documentário traz um panorama da história da AIDS, apresenta campanhas de prevenção, discute a questão do "supervírus" e destaca que, ainda hoje, a AIDS acomete muitas pessoas. Durante a exibição do filme informativo, paramos e explicamos pontos destacados nos relatos, abrindo espaço para os alunos perguntarem e esclarecerem suas dúvidas. Muitas surgiram, mas realçamos aqui o desconhecimento, dito pelos próprios estudantes, sobre a história da AIDS, o impacto mundial que a doença causou; e o preconceito que os portadores do vírus sofrem.

Decidimos ir interrompendo o documentário ao longo da exibição para, justamente, possibilitarmos estas discussões ao longo de toda a aula e não somente nos minutos finais. Para além de "alarmar" os estudantes, como já destacamos, pensamos no caráter reflexivo que o filme poderia provocar. Ao tratarmos do HIV deste modo (o que se aplica para outras

\footnotetext{
${ }^{7}$ Disponível em: https://globosatplay.globo.com/globonews/v/5477684/. Acesso em fev. 2019.
} 
infecções sexualmente transmissíveis) contribuímos com informações sobre cuidados com o corpo e o impacto que doenças sexualmente transmissíveis podem acarretar. O que de maneira alguma pode ser compreendido como um incentivo ao sexo ou um estímulo para que realizem. Objetivamos construir aulas, no que tange a informações e conhecimentos sobre HIV/AIDS, que se afastem do senso comum, do preconceito e de informações equivocadas que perpassam desde a transmissão até os mecanismos de prevenção e tratamento.

Conhecer as formas de prevenção e as estratégias utilizadas para tal pode contribuir para o combate à disseminação do HIV. Em outras palavras, ao passo que conhecemos métodos de prevenção como a PREP (Profilaxia Pré-Exposição ao HIV), ou como a PEP (profilaxia pós-exposição), diminuem-se as chances de ser infectado pelo vírus. Nessa perspectiva, construímos uma aula com dois períodos (no mês de abril) na qual nos utilizamos do equipamento multimídia e de apresentação em slideshow para melhor ilustrar estas ferramentas de prevenção. Tencionamos com os alunos que a PREP se utiliza da combinação de drogas/medicamentos que atuam para impedir que o HIV se espalhe no organismo. Ou seja, é uma droga para evitar que uma pessoa que não possui o HIV, quando se exponha ao vírus, não o adquira. Pela mesma via preventiva, trouxemos à tona a PEP, que consiste no uso de medicamentos, tomados por 28 dias seguidos por indivíduos soronegativos, para evitar sua possível mudança sorológica - entretanto, precisa ser iniciada em, no máximo, até 72 horas após a exposição de risco (MORAES-FILHO et al., 2018).

A maioria dos estudantes desconhecia a existência destes medicamentos de prevenção. Para se ter ideia, entre as duas turmas de oitavos anos com as quais trabalhamos, média de 25 alunos cada, apenas uma estudante manifestou conhecimento sobre PEP e PREP. Os alunos demonstraram ainda confusão na hora de definir o que é PREP e PEP - dizemos isso tanto pelas dúvidas que surgiram no dia da aula quanto pelo resultado da avaliação/prova que fizemos em semanas posteriores. Entretanto, a ideia de que estes medicamentos são preventivos, encontrados de forma gratuita em unidades de saúde e que um deles precisa ser ministrado em curto período de tempo foram informações pontuadas na prova da maioria dos alunos. Não estamos querendo dizer que a nossa aula/atividade "foi um sucesso" e constatamos isso com uma avaliação. Entendemos, pois, que construímos um espaço de diálogo e construção de conhecimentos, de trocas de experiências, saberes, que pode ser percebido não somente num instrumento avaliativo, mas em outras situações/momentos que ainda vamos discorrer neste artigo.

Como forma de retomar as discussões realizadas e tornar os alunos agentes multiplicadores de informações sobre HIV/AIDS na comunidade, elaboramos (entre os meses 
de maio e junho) um questionário no qual cada estudante tinha de realizar com um indivíduo que não fizesse parte da escola onde estudam. Construímos as perguntas do questionário com base na "Pesquisa de conhecimentos, atitudes e práticas na população brasileira" (BRASIL, 2011). Essa é uma pesquisa que visa monitorar a epidemia de HIV/AIDS e o controle das DST/AIDS/HIV no Brasil. Já com relação ao questionário que desenvolvemos, as cinco primeiras perguntas (com opção de resposta "discorda", "concorda", e "não sabe") envolveram formas de transmissão do vírus; aparência das pessoas soropositivas; e prevenção. Como pode ser visto no quadro abaixo:

Quadro 2 - Questionário adaptado sobre HIV/AIDS.

\begin{tabular}{|l|}
\hline $\begin{array}{l}\text { 1) O risco de transmissão do vírus HIV pode ser reduzido se uma pessoa tiver relações sexuais somente com } \\
\text { parceiro fiel e não infectado. }\end{array}$ \\
\hline 2) Uma pessoa com aparência saudável pode estar infectada pelo vírus HIV. \\
\hline 3) Usar preservativo é a melhor maneira de evitar que o vírus HIV seja transmitido durante a relação sexual. \\
4) Uma pessoa pode ser infectada com o vírus HIV compartilhando talheres, copos ou refeições. \\
\hline $\begin{array}{l}\text { 5) Uma mulher grávida que esteja com o vírus HIV e recebe um tratamento específico durante a gravidez e no } \\
\text { momento do parto diminui o risco de passar o vírus HIV para o seu filho. }\end{array}$
\end{tabular}

Fonte: elaborado pelos Autores.

As próximas duas perguntas do questionário envolveram PREP e PEP, a saber: 1) Você sabe o que é Prep (Profilaxia Pré-Exposição ao HIV)?; 2) Você sabe o que é Pep (Profilaxia Pós-Exposição de risco)?. As possibilidades de resposta eram "sim" ou "não". Por último, deixamos a seguinte pergunta com resposta dissertativa: "você tem alguma informação, história ou acontecimento que envolva HIV/AIDS para contar?”.

O questionário nos possibilitou além da retomada de muitos assuntos discutidos com os alunos ao longo das aulas a multiplicação dos conhecimentos aprendidos. Os estudantes se sentiram motivados para realizarem o trabalho, pois alguns deles, por exemplo, solicitaram mais de um questionário - já que queriam aplicar para mais pessoas da comunidade. Uma aluna definiu a UBS próxima da sua casa como local de aplicação do questionário; assim como outros decidiram aplicar aos familiares e vizinhos. Orientamos que eles precisavam não apenas coletar dados, mas, sim, aproveitar o momento para compartilharem o que sabem. Por isso, ao final do questionário, quando os entrevistados respondiam desconhecer as estratégias de prevenção PREP e PEP, por exemplo, os alunos tinham o compromisso de explicar o que é, a gratuidade da medicação, e a disponibilidade em postos de saúde.

Finalizada a aplicação do questionário pelos alunos, no período de duas aulas, compilamos os dados na lousa. Explicamos melhor. Para termos ainda uma ideia de como 
foram as respostas do questionário, numeramos as perguntas na lousa e, ao lado da mesma, inserimos as possibilidades de respostas das cinco primeiras: "discorda"; "concorda"; "não sabe". E "sim" e "não" para as duas perguntas seguintes. A partir disso, líamos a pergunta e a alternativa. A cada alternativa lida, os alunos levantavam o braço para a marcada no seu questionário. Tivemos, assim, um panorama das respostas. O que nos possibilitou perceber que, entre as duas turmas, a maioria das pessoas entrevistadas desconhecia sobre PREP e PEP; assim como a maioria também não apresentou informações equivocadas sobre a aparência das pessoas soropositivas, o uso de preservativo como forma de prevenção e a transmissão do vírus via vertical (da mãe para o filho). Certamente nosso objetivo não era "validar cientificamente" a pesquisa ou tornar estes números em "dados oficiais". Nossa intenção foi promover, mais uma vez, o compartilhamento de informações. Possibilitar que os estudantes entrassem em contato com o questionário dos colegas de turma e tivessem acesso aos resultados obtidos.

Buscamos problematizar os dados construídos pelos alunos, recolhemos o questionário e tivemos acesso às histórias contadas pelos seus entrevistados. Muitas histórias íntimas, com relatos sobre amigos, afilhados, familiares. Entretanto, não vamos discorrer estas vivências aqui por não termos a autorização para compartilhá-las.

Por fim, a partir de todas as atividades desenvolvidas ao longo do primeiro semestre de 2019, propomos no mês de agosto, aos alunos elaborarem um jornal/folheto informativo sobre HIV/AIDS. Este material, inicialmente, foi construído no caderno de ciências. Cada aluno tinha de desenvolver o seu texto informativo individualmente, situar o local onde ficariam as imagens e um título. Após isso, o primeiro autor deste artigo e também professor da turma, corrigiu os jornais/folhetos e, então, solicitou que o material elaborado no caderno fosse passado para o formato digital.

Com os trabalhos dos alunos já em formato digital foi possível tirar cópias e divulgálos para a comunidade escolar. Escolhemos a feira de ciências da escola para tal divulgação por ser um evento que abrange todas as turmas da escola e tem a participação tanto dos alunos quanto dos responsáveis e comunidade em geral. A feira de ciências aconteceu no final do mês de agosto, em um sábado e teve, em alguns minutos, mais de 200 cópias dos jornais/folhetos divulgadas. 


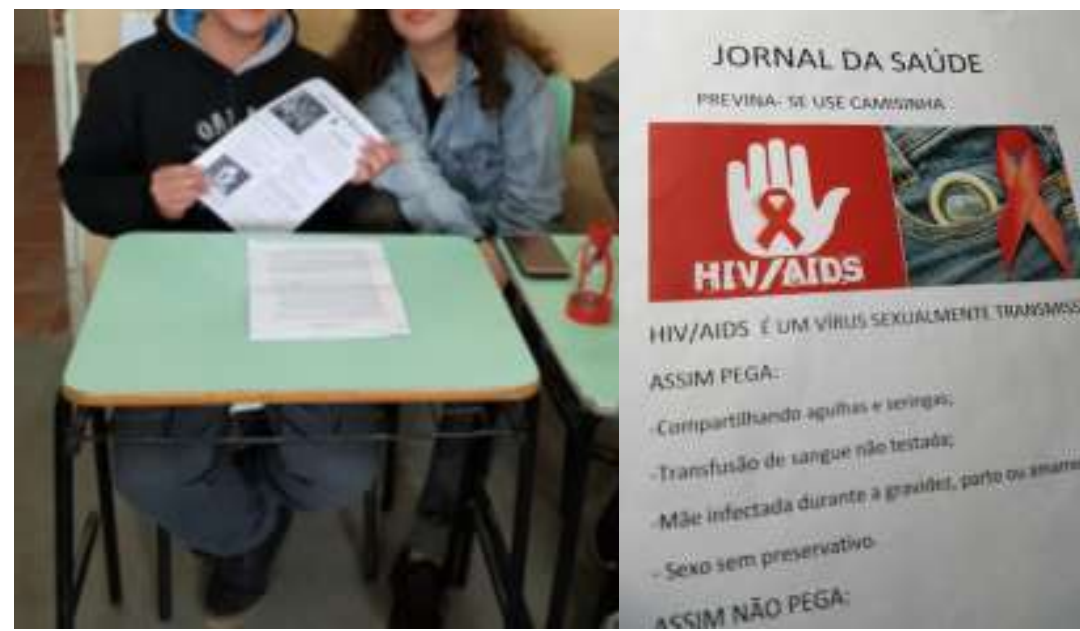

Figura 1 - Foto dos jornais/folhetos informativos.

Fonte: Tirada pelos autores.

A elaboração do jornal/folheto se deu durante duas semanas e como um trabalho a ser realizado em casa. Por meio dele, podemos retomar a maioria dos assuntos que foram discutidos com os alunos. Muitos dos alunos preocuparam-se em criar uma espécie de tabela, na qual tinha por objetivo listar as formas de contágio e as maneiras de prevenção do HIV. As imagens inseridas, como pode ser percebido na figura 1, ilustravam o laço vermelho como símbolo de solidariedade e preservativos. Também orientamos os alunos a terem cuidado com o vocabulário e a maneira como os textos e frases seriam postos nos jornais/folhetos, sendo que divulgaríamos para pessoas de diferentes faixas etárias e grau de instrução.

\section{Conclusões}

A parceria estabelecida com a UBS através do PSE contribuiu para que tivéssemos atividades mais aproximadas do contexto do município de Pelotas - RS. Além disso, ao longo de todas as atividades e momentos propostos para a discussão, buscamos trazer diferentes informações acerca do HIV/AIDS. Perpassamos pela a história da doença no mundo, pela testagem, mecanismos de prevenção, realidade relatada pelas próprias pessoas infectadas pelo vírus, assim como consideramos a fala dos alunos. Eles puderam expor suas opiniões, dúvidas e questionamentos.

Pontuamos em diferentes partes do texto aqui apresentado que objetivamos que os alunos refletissem sobre o que estava sendo exposto, discutido. Ou seja, nossa ideia baseou-se no pensamento, na ampliação e construção de conhecimentos e não na imposição de informações como "use camisinha". Não se trata de negar a importância do uso do preservativo, ou deste método de barreira contra as mais diferentes infecções, mas, sobretudo, de expor aos estudantes todo o contexto político, biológico, social e cultural acerca do 
HIV/AIDS. Em meio a isso, os alunos podem ir definindo, a partir das ideias alargadas nas discussões, sobre as ferramentas que podem utilizar e as maneiras que querem se portar diante de todo este cenário do qual fazemos parte enquanto sociedade.

Certamente esperamos que, assim, possamos contribuir na construção de adultos informados, atentos, críticos e cientes do enfrentamento que devemos ter diante de toda e qualquer forma de discriminação, preconceito e marginalização.

\section{Referências}

ALMEIDA, M. R. C. B. LABRONICI, L. M. A trajetória silenciosa de pessoas portadoras do HIV contada pela história oral. 2006. Disponível em: <https://www.scielosp.org/pdf/csc/2007.v12n1/263-274/pt>. Acesso em: 15 janeiro 2020.

BRASIL. Ministério da Saúde - Secretaria de Vigilância em Saúde - Departamento de Vigilância, Prevenção e Controle das Infecções Sexualmente Transmissíveis, do HIV/Aids e das Hepatites Virais. Brasília: Ministério da Saúde, 2018. Disponível em: <http://www.aids.gov.br/pt-br/pub/2018/boletim-epidemiologico-hivaids-2018>. Acesso em: 10 fevereiro 2019.

BRASIL. Ministério da Saúde. Pesquisa de conhecimento, atitudes e práticas na população brasileira / Ministério da Saúde. Secretaria de Vigilância em Saúde. Departamento de DST, Aids e Hepatites Virais. Brasília: Ministério da Saúde, 2011. Disponível em: $<$ http://bvsms.saude.gov.br/bvs/publicacoes/pesquisa_conhecimentos_atitudes_praticas_pop ulacao_brasileira.pdf $>$. Acesso em: 10 fevereiro 2019.

GUIMARÃES, R.; FERRAZ, A. F. A interface AIDS, estigma e identidade - algumas considerações. Rev. Min. Enf., v. 6, p. 77-85, 2002.

MORAES-FILHO, I. M.; NERY, M. R. T.; SANTOS, S. S.; FÉLIS, K. C.; FRASCA, L. L. M.; SANTOS, O. P. A importância do método de prevenção à infecção por HIV denominado de PREP - profilaxia pré-exposição ao HIV. Rev Inic Cient Ext. v. 1, Ed. Esp. 405-406, 2018.

PSE. Programa Saúde na Escola. 2019. Disponível em: < http://portal.mec.gov.br/expansaoda-rede-federal/194-secretarias-112877938/secad-educacao-continuada-223369541/14578programa-saude-nas-escolas >. Acesso em: 10 fevereiro 2019.

RIBEIRO, P.; RIZZA, J. L.; MAGALHÃES, J. C.; QUADRADO, R. Educação e sexualidade: identidades, famílias, diversidade sexual, prazeres, desejos, homofobia, AIDS. 2. Ed. Rio Grande: Editora da FURG, 2008, 428p. 